\title{
Scaling Politically Meaningful Dimensions Using Texts and Votes
}

\author{
Benjamin E. Lauderdale \\ Associate Professor \\ Department of Methodology \\ London School of Economics \\ b.e.lauderdale@lse.ac.uk
}

\author{
Tom S. Clark \\ Asa Griggs Candler Professor \\ Department of Political Science \\ Emory University \\ tom.clark@emory.edu
}

September 25, 2013

\begin{abstract}
Item response theory models for roll-call voting data provide political scientists with parsimonious descriptions of political actors' relative preferences. However, models using only voting data tend to obscure variation in preferences across different issues due to identification and labeling problems that arise in multidimensional scaling models. We propose a new approach to using sources of metadata about votes to estimate the degree to which those votes are about common issues. We demonstrate our approach with votes and opinion texts from the U.S. Supreme Court, using Latent Dirichlet Allocation to discover the extent to which different issues were at stake in different cases and estimating justice preferences within each of those issues. This approach can be applied using a variety of unsupervised and supervised topic models for text, community detection models for networks, or any other tool capable of generating discrete or mixture categorization of subject matter from relevant vote-specific metadata.
\end{abstract}

Word Count: 8,291

(forthcoming, American Journal of Political Science) 


\section{INTRODUCTION}

A fundamental component of contemporary political science is concerned with measuring political actors' preferences. A primary question in this research endeavor concerns the dimensionality of preferences. Qualitatively-oriented scholars of legislatures and courts often argue preferences are in fact highly multi-dimensional, while quantitative analysts generally argue preferences can be described accurately and succinctly as low-dimensional. These arguments are usually made by reference to statistical, rather than substantive, criteria for dimensionality. How many dimensions do we need to fit the data well? Or at least well enough? The answer is usually one dimension, and only rarely more than two dimensions (Poole and Rosenthal 1997; Voeten 2000; Grofman and Brazill 2002; Clinton, Jackman and Rivers 2004; Hix, Noury and Roland 2006).

At the same time, qualitative studies of politics often suggest that preferences are highly multidimensional in consequential ways. For example, that Supreme Court justices' preferences vary across substantive areas of the law has affected the extent to which individual members of the Court are pivotal (e.g., Lauderdale and Clark 2012) and can influence the direction of the law (e.g., Jeffries 1994; Stern and Wermiel 2010). In other contexts, multidimensional preferences give rise to well-known social choice pathologies, and the study of political institutions has been concerned with how those institutions help resolve those problems. Unfortunately, because scholars increasingly focus on low-dimensional preferences, we often miss these important theoretical puzzles. What is more, a focus on low-dimensional preferences limits our ability to answer central puzzles in politics. For example, does a change in the effective dimensionality of a voting body induce change to supposedly stabilizing institutions? These and other limitations suggest a need for the ability to study high-dimensional preferences in political institutions.

Two major obstacles have prevented scholars from moving beyond two dimensions. First, the tools scholars use to reduce voting behavior into latent ideal point estimates do not provide any information about the substantive interpretation of recovered dimensions. As a consequence, the analyst must specify how the estimated dimensions are related to interpretable political cleavages. This is difficult to do, because it requires implicitly or explicitly constraining all possible linear 
transformations of the latent space, and the number of possible linear transformations grows rapidly with the dimensionality (Rivers 2003). Second, the binary data most commonly used to estimate preferences (votes) are insufficiently informative to support analyses beyond one or two dimensions using multidimensional scaling methods. Improvements in fit tend to fall off very quickly, not necessarily because the political world has only one or two dimensions, but because the limited voting data we have can be predicted well enough by one or two estimated dimensions, given the numbers of voters and votes that are typically present. Political scientists using ideal point estimates have therefore focused heavily on these highly simplified measures of preferences: just one or two measured dimensions which may combine a wide range of substantive political issues across which preferences are correlated, but not perfectly so. The fundamental problem is that it not usually possible to figure out which of these underlying substantive issues a given vote is about, if one looks at nothing more than the observed pattern of votes.

We introduce a generally applicable method for resolving these two problems. The key innovation is that we bring metadata about votes to bear on the problem of describing legislative and judicial behavior. While different kinds of metadata can be used for this purpose, in this paper we focus on the use of vote-specific texts (e.g. bills, opinions, debates) to identify which of many issue dimensions a given vote was about. This is in contrast to standard models that try to infer this information from the pattern of roll call voting behavior. By using metadata about which votes are similar in substance, we can statistically identify many-dimensional estimates that improve fit, even when appropriately penalized for the additional uncertainty that results from estimating additional parameters.

A range of models exist for modeling texts as mixtures of, or as discrete members of, topics, under the assumption that different topics have different characteristic distributions of term usage. As we show in Section 2, these discrete or mixture categorizations can be used to solve an identification problem in multidimensional ideal point estimation. Ideal point estimators effectively discover which legislators or judges tend to vote together, but not what they are voting about. In contrast, topic models discover the topic or topics being discussed in a series of texts, but not what is being said about those topics. Roughly speaking, combining the two allows us to discover what issue a 
vote is about from textual data and how legislators or judges respond to that issue through their votes. In this paper, we demonstrate this combination using Latent Dirichlet Allocation (LDA) for textual data (Blei, Ng and Jordan 2003) and Item Response Theory (IRT) models for ideal point estimation from roll call data (Jackman 2001). In Section 3 we describe the technical details of how we combine MCMC simulation of the LDA and IRT models, targeting optimal prediction of the roll call votes rather than the texts. We recover a list of issues/dimensions, each with characteristic terms and spatial preference estimates.

In Section 4, we apply our model to the U.S. Supreme Court, using the texts of opinions as our source of information about the issues at stake in each decision. In the data we consider, we find the best fit under models with 20-30 issue dimensions. These issue dimensions are substantively meaningful (search and seizure; patent and copyright; etc.) and are discovered from the textual data. Identifying the dimensions this way greatly reduces the issues of identification and interpretation generally associated with standard multidimensional ideal point models. In the conclusion, we discuss a range of alternative methods that could be used to fulfill the role that the LDA model plays in this paper. The same approach can be applied using any method of calculating topic assignments: supervised or unsupervised, with discrete or mixture assignments, using textual or other data that conveys information about topical similarity.

\section{COMBINING TEXTS AND VOTES}

Scholars have increasingly argued that additional information is required to make sense of spatial preference estimates in a variety of contexts, ranging across the EU Parliament (Hix and Crombez 2005), the US Congress (Crespin and Rohde 2010), the Brazilian legislature (Zucco, Jr and Lauderdale 2011), and the US Supreme Court (Lauderdale and Clark 2012). The goal of leveraging metadata is to overcome the limitations of multidimensional scaling models, which only recover dimensions in the voting behavior that maximize statistical fit, even when those dimensions conflate many substantive dimensions scholars want to study. Metadata about the subject of particular votes has the potential to provide the estimator with information about the substantive meaning 
of the dimensions.

To understand the intuition, consider a comparison between scaling models in political science and in educational testing. Major educational tests like the SAT and ACT are split into sectionsmath, verbal, etc.- - based on the test designers' knowledge of what the questions are about. This is viewed as preferable to attempting to recover multiple traits from an undifferentiated collection of test items, because it does not require the scaling model be able to differentiate the questions into different topics. By contrast, traditional multidimensional scaling in political science is akin to educational test in which the verbal, math, and other questions are collectively scaled in two (or more) dimensions, without any labeling of which questions are expected to test which abilities. The consequence is uncertainty about what is being measured, which is avoided in the educational testing context by writing separate tests that each aim to test primarily a single ability of interest. Fortunately, while political actors do not usually provide researchers tidy discrete categorizations of which votes are about which issues, they do provide metadata information - texts of bills, opinions, oral arguments and legislative debates; citation data to legal statutes and precedent cases; etc.that can help us figure out what their votes were about and what preference dimensions those votes reveal. While manual coding of votes into discrete categories is a viable approach in some applications, political scientists often examine large sets of votes, making automatic processing of metadata valuable.

We focus on textual metadata in this paper. The most widely analyzed quantitative feature of texts - relative usage of different terms - tends to reveal a great deal about what issues are being discussed. For example, consider the Supreme Court case Florence vs. Board of Chosen Freeholders of the County of Burlington, decided in 2012. This case considered whether police need to have specific reasons to suspect contraband in order to conduct a strip search of an individual who is already being jailed. The majority opinion repeatedly uses terms like "jail" (50 appearances), "search" (45), "detainee" (37), "inmate" (28), "contraband" (27), "drug" (14) that also appear frequently in some other Court decisions, but appear rarely in most opinions. One can infer that the subject of the Florence case is more similar to opinions that use terms like "detainee" and "search" than opinions that do not use those terms. Of course, there are other terms like "petitioner" (23) 
which are much more generic features of Supreme Court opinion texts and provide little information about which issues are at stake. Using a statistical model of text, we can determine a mix of issues implicated in the opinions. Our approach relies on the assumption that this mix also reveals which preference dimensions are relevant to this vote. A text that is purely about a single issue is assumed to imply a vote that only depends on preferences on that issue.

Consider a simple example, with just two issue dimensions. Voter $i$ has a position $\theta_{i A}$ on issue $\mathrm{A}$ and $\theta_{i B}$ on issue $\mathrm{B}$. The question for any given vote is: to what extent is that vote is about issue A and to what extent is that vote is about issue B? Our approach is to use the text to estimate the answer. Specifically, let $\lambda_{A}$ represent the degree to which the vote is about issue $\mathrm{A}$ and $\lambda_{B}$ represent the degree to which the vote is about issue $\mathrm{B}$, where $0 \leq \lambda_{A}, \lambda_{B} \leq 1$ and $\lambda_{A}+\lambda_{B}=1$. Figure 1 shows several special cases for this two dimensional spatial model. Panel A shows possible cutting lines - the lines separating yes voters from no voters - if the vote is entirely about issue A $\left(\lambda_{A}=1, \lambda_{B}=0\right)$. Different cutting lines will correspond to different coalitions of yes and no voters, but only $\theta_{i A}$ will predict the behavior of any voter $i$. On such votes, preferences with respect to issue $\mathrm{B}$ are irrelevant to voting behavior. Panel B shows the corresponding case for votes that are purely on issue B.

Panel $\mathrm{C}$ shows the case of a bill that is equally about issue $\mathrm{A}$ and issue $\mathrm{B}\left(\lambda_{A}=0.5, \lambda_{B}=\right.$ 0.5). We assume that the weight each dimension plays in each vote is directly proportional to the proportion of text coming from each issue. We measure a vector $\boldsymbol{\lambda}_{\mathbf{j}}$ such that each element $0 \leq \lambda_{j d} \leq 1$ and $\sum_{d=1}^{D} \lambda_{j d}=1$ from the text, and then apply these relative weights to the voter $i$ 's positions $\theta_{i d}$ across dimensions $d$ in determining her latent voting preferences on vote $j$. These are non-trivial identifying assumptions: they determine how observed votes that mix multiple issues shape our estimates of preferences across those issues.

Panel D shows cutting lines that are impossible under the model. These are cutting lines that would describe coalitions of issue A conservatives with issue B liberals opposing coalitions of issue A liberals with issue B conservatives. While such coalitions are of course conceptually and politically possible, ruling them out by assumption is a consequence of using a vector of mixture weights $\boldsymbol{\lambda}$ to identify the rotation of the cutting line. A valuable side-effect is that this restriction on which 


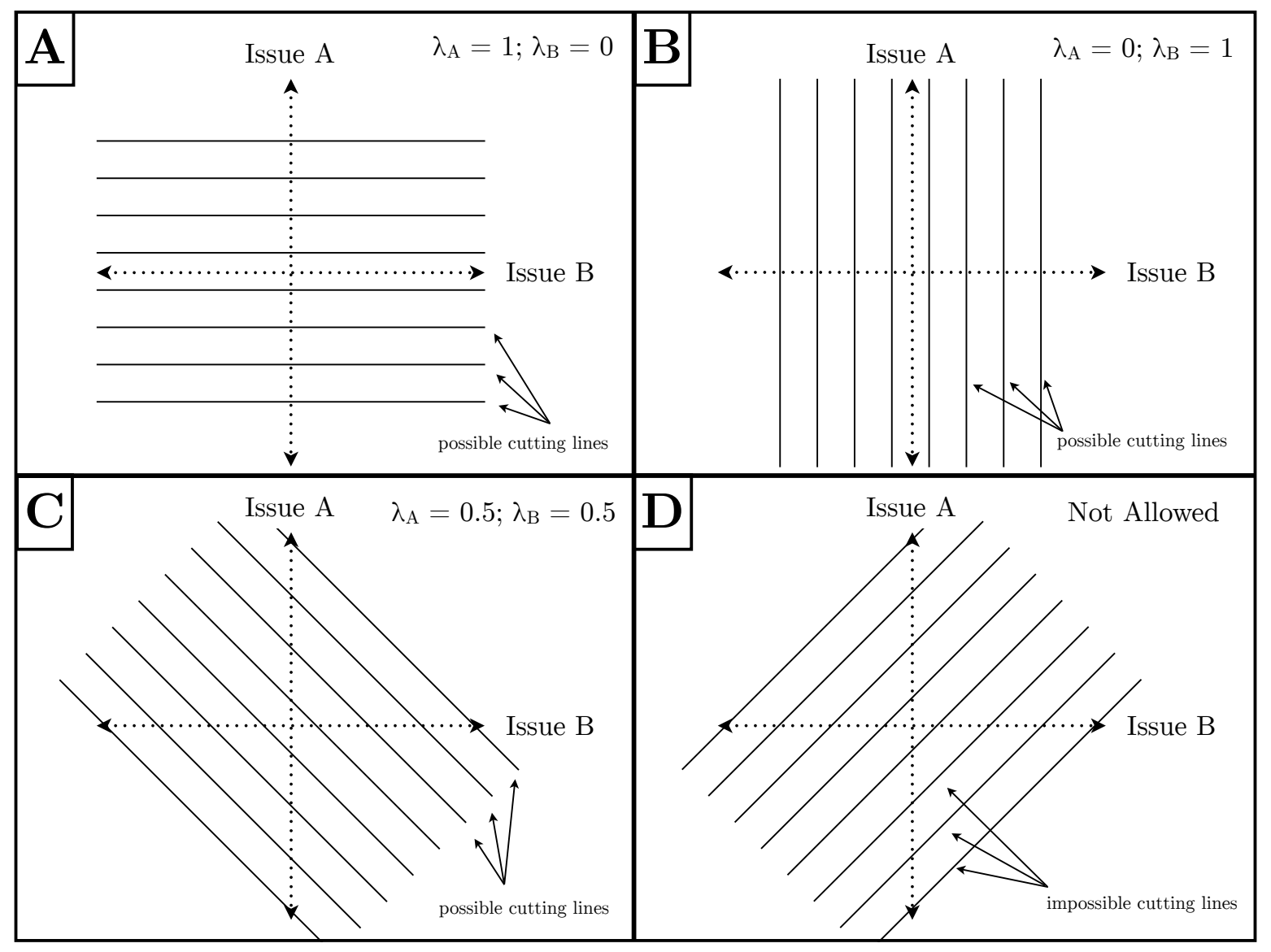

Figure 1: Cutting lines for several mixtures of two topics. The top left panel (A) shows possible cutting lines that can be estimated given a text that is entirely drawn from Issue A. The top right panel (B) shows possible cutting lines that can be estimated given a text that is entirely drawn from Issue B. The bottom left panel (C) shows possible cutting lines that can be estimated given a text that is equally drawn from Issues A and B. The bottom right panel shows cutting lines that are impossible under the model. 
cutting lines - more generally, hyperplanes - are allowed, enforces consistent liberal/conservative labeling across dimensions. Nearly all of the possible rotations and reflections of the space that do not change predicted voting patterns under a standard multidimensional IRT model (Rivers 2003) do change predicted voting patterns under our model, because of this restriction.

In principle, we could estimate the orientation of the cutting hyperplanes for each vote using any of a variety of models to map textual data about votes into vectors of mixture components $\boldsymbol{\lambda}_{\mathbf{j}}$. Latent Dirichlet Allocation (LDA) is well-suited to generating suitable $\boldsymbol{\lambda}_{\mathbf{j}}$, using minimally processed text and without prior specification of topics. Many other approaches are possible, including discrete topic models for text or expert issue codings, that would only allow a single preference dimension to predict each vote.

\section{METHODS}

\subsection{Model Specification}

Our model has two major components. We first estimate the latent distribution of topics across and within a series of documents using LDA. We then use the posterior estimates of the distribution of topics for each text from the LDA model to model the extent to which the vote on that text was about each dimension. The LDA portion of the model is identical in specification and implementation to previous MCMC implementations (Griffiths and Steyvers 2004; Heinrich 2009); however we change some notation for compatibility with the notation of the voting model. The notation for indices, parameters, and data in the model are listed in Table 1.

The LDA model terminology refers to words, terms, topics, and documents. A document is considered a sequence of words. Each word is an instance of a particular term. For example, the sentence "The Republican and the Democrat disagreed." has six words and five terms (the term "the" appears as both the first and fourth word). LDA assumes the relative frequency of different terms in different documents reveals which topics are being discussed. The model can be summarized as follows. Each word that appears in a document is assumed to have a latent 


\begin{tabular}{|c|l|l|}
\hline & $i \in 1,2, \ldots, N$ & index for voters \\
& $j \in 1,2, \ldots, M$ & index for votes/documents \\
& $d \in 1,2, \ldots, D$ & index for dimensions/topics/issues \\
& $k \in 1,2, \ldots, L_{j}$ & index for words in text for vote $j$ \\
& $t \in 1,2, \ldots, V$ & index for terms in vocabulary \\
\hline Latent & $w_{j k} \in 1,2, \ldots, V$ & observed term for each word $k$ in document $j$ \\
and & $z_{j k}^{*} \in 1,2, \ldots, D$ & latent topic of each word $k$ in document $j$ \\
Observed & $y_{i j} \in 0,1$ & vote $j$ of voter $i$ \\
Data & $y_{i j}^{*}$ & latent vote $j$ of voter $i$ \\
\hline & $\varphi_{t d}$ & mixture component of term $t$ in topic $d$ \\
Parameters & $\lambda_{j d}$ & mixture component of topic $d$ in document $j$ \\
to be & $\alpha_{j}, \beta_{j}$ & discrimination parameters for each vote $j$ \\
Estimated & $\theta_{i d}$ & ideal point for voter $i$ on topic $d$ \\
& $\rho$ & prior correlation of ideal points across topics \\
\hline
\end{tabular}

Table 1: Model notation.

topic. The latent topic $z_{j k}^{*}$ for word $k$ in document $j$ is assumed to be a multinomial draw from the distribution of topics in that document: $z_{j k}^{*} \sim \mathcal{M}\left(\boldsymbol{\lambda}_{\mathbf{j}}\right)$. The observed term $w_{j k}$ for word $k$ in document $j$ is assumed to be a multinomial draw from the distribution of terms in the latent topic $z_{j k}^{*}: w_{j k} \sim \mathcal{M}\left(\boldsymbol{\varphi}_{z_{j k}^{*}}\right)$. The multinomial parameter vector describing the distribution of terms $t$ within each topic $d$ is assumed to be a draw from a Dirichlet distribution with hyper parameters $\delta: \varphi_{\mathrm{d}} \sim \mathcal{D}(\delta)$. The multinomial parameter vector describing the distribution of topics $d$ within each document $j$ is assumed to be a draw from a Dirichlet distribution with hyperparameters $\gamma$ : $\boldsymbol{\lambda}_{\mathbf{j}} \sim \mathcal{D}(\gamma)$. The model assumes that a set of topics describe variation in term use across the corpus of documents: the topic for each word location in each document is a multinomial draw from a distribution of topics characteristic of that document, and the actual term that appears in that word location is a multinomial draw from the distribution of terms characteristic of that topic.

We are particularly interested in the $\boldsymbol{\lambda}_{\mathbf{j}}$, the vectors of mixture components describing the fraction of the text for each vote $j \in 1,2, \ldots, M$ that is in each topic $d \in 1,2, \ldots, D$. We are also interested in the term frequency distributions $\boldsymbol{\varphi}_{\mathbf{d}}$ for each topic, since these allow us to substantively label the topics by calculating which terms are most indicative of a word being drawn from each topic. 
In $D$ dimensions, the Jackman (2001) model for observed votes $y_{i j}$ has the following form:

$$
\begin{aligned}
& y_{i j}= \begin{cases}1 & \text { if } y_{i j}^{*} \geq 0 \\
0 & \text { if } y_{i j}^{*}<0\end{cases} \\
& y_{i j}^{*} \sim \mathcal{N}\left(\alpha_{j}+\sum_{d=1}^{D} \beta_{j d} \theta_{i d}, 1\right)
\end{aligned}
$$

Our model is a restriction of this model: we reduce $\beta$ from a vector of length $D$ for each vote $j$ to a scalar for each vote $j$. In the conventional multidimensional IRT model, the vector of discrimination parameters describes the degree to which each latent dimension predicts the latent outcome. In our model, the relative degree that each latent dimension predicts the latent outcome is determined by the text, and only the degree to which the resulting weighted average of the dimensions predicts the outcome is estimated from the voting data. From the LDA model on the texts, we get a Ddimensional vector $\boldsymbol{\lambda}_{\mathbf{j}}$ describing the fraction of vote $j$ 's text that comes from each topic $d$. This vector determines the relative weight of each ideal point dimension in determining the latent vote:

$$
y_{i j}^{*} \sim \mathcal{N}\left(\alpha_{j}+\sum_{d=1}^{D} \beta_{j} \lambda_{j d} \theta_{i d}, 1\right)
$$

This can be rewritten in terms of vote-specific $1 \mathrm{D}$ ideal points $\theta_{i j}$ :

$$
\begin{aligned}
y_{i j}^{*} & \sim \mathcal{N}\left(\alpha_{j}+\beta_{j} \theta_{i j}\right) \\
\theta_{i j} & \equiv \sum_{d=1}^{D} \lambda_{j d} \theta_{i d}
\end{aligned}
$$

The $\theta_{i d}$ are issue-specific ideal points for each voter, which each correspond to preferences on a vote with corresponding text entirely on a single topic/issue. Combined with the estimated mixture of topics $\boldsymbol{\lambda}_{\mathbf{j}}$ for the document associated with a particular vote $j$, one can use these issue-specific ideal points calculate a vote-specific ideal point $\theta_{i j}=\sum_{d=1}^{D} \theta_{i d} \lambda_{j d}$. 


\subsection{Model Priors and Simulation}

For the LDA model, the choice of priors determines the symmetry and sparsity of the recovered topics. We use symmetric Dirichlet priors, which yields topics of roughly equal total text length. While this may not be ideal for all topic modeling applications (Wallach, Mimno and McCallum 2009), it ensures that roughly equal quantities of voting data are brought to bear on estimating each dimension. Having chosen symmetric priors, we still must choose the values of the hyperparameters $\gamma$ and $\delta$. Smaller values of $\gamma$ lead to more decisive assignments of documents to a small set of topics. Smaller values of $\delta$ lead to more decisive assignments of terms to a small set of topics. We are more interested in decisive assignment of documents to topics than terms to topics, so we assume different values than those recommended in the literature (Griffiths and Steyvers 2004). We set the hyperparameter for the assignment of topics within documents equal to $\gamma=1 / D$ and the hyperparameter for the assignment of terms to topics $\delta=1$.

For the IRT model, we use normal priors with mean 0 and variance 4 for the vote parameters $\alpha_{j}$ and $\beta_{j}: \alpha_{j} \sim \mathcal{N}(0,4)$ and $\beta_{j} \sim \mathcal{N}(0,4)$. For the ideal points, we assume a multivariate normal prior with mean 0 , and a covariance matrix with 1 on the diagonal and $\rho \in(0,1)$ off the diagonal. The mean of 0 centers the ideal point scale and the diagonal components of the variance matrix defines the spread of the ideal point scale. The positive off-diagonal elements of the variance matrix orients all the issue-specific dimensions with conservatives at the same ends and provides shrinkage of ideal points in each dimension to their common mean across dimensions. We put a uniform prior over positive values of this correlation: $\rho \sim \mathcal{U}(0,1) .^{1}$

We estimate our model by MCMC simulation. Our estimator is a built from the LDA collapsed Gibbs sampler described by Griffiths and Steyvers (Griffiths and Steyvers 2004) and the IRT Gibbs sampler described by Jackman (Jackman 2001). Rather than estimating a fully joint model, we simulate the LDA model, and then condition the IRT model on the current draw of $\boldsymbol{\lambda}$ from the LDA model. We describe our sampling procedure in the online appendix.

${ }^{1}$ Note that a more flexible covariance structure between dimensions could be estimated if a large number of voters were available. 


\subsection{Model Selection}

Choosing the best number of topics for a topic model is a difficult problem in general, and several additional considerations are introduced by our application of the topic mixture vector $\boldsymbol{\lambda}$ to predicting votes. A common approach to assessing the best number of topics in LDA modeling is to assess the model's perplexity under a number of topics (Blei, Ng and Jordan 2003). Perplexity is a measure that evaluates how well the model predicts held-out textual data. This criterion is used to find when adding more topics stops making appreciable increases in the model's predictive power; however such a criterion is only appropriate if the goal is predicting the textual data. Our goal, by contrast, is predictions of roll call votes. If we estimate too few topics, we will fail to find variation in preferences across issues that could improve the predictive power of the ideal point estimates. If we estimate too many topics, we will have only a few votes on each issue and will lack sufficient data to learn much about preferences about that issue. To balance these concerns about having enough votes per topic with having enough topics to adequately describe the voting space, we use the Deviance Information Criterion (DIC, Spiegelhalter et al. (2002)) to optimize predictive power of the ideal points for votes. Because we estimate the LDA and IRT models separately, we can calculate the DIC purely on the basis of the latter. Where the deviance $D(\Theta)=-2 \log \mathcal{L}(\Theta)$, we calculate the DIC as two times the mean posterior deviance minus the deviance of the mean posterior estimates of the parameters:

$$
D I C=2 \overline{D(\Theta)}-D(\bar{\Theta})
$$

\subsection{Model Features and Limitations}

Our model assumes that all voters are voting on the same mixture of dimensions: if $35 \%$ of the text is from topic A and $65 \%$ from topic B, then every voters' preference is a 35-65 weighted average of their preferences on dimensions $\mathrm{A}$ and $\mathrm{B}$. This assumption is required for model identification, but there are two possible substantive objections in our application. First, the proportions of text are 
surely not identical to the relative importance that the justices put on each of the two dimension in making their decisions. Second, the justices may differ in which dimension they think is most relevant to a given case. Even if this is the case, our approach is a reasonable approximation, since even if the justices disagree about which area of law is controlling, their preferences in all the relevant directions may be relevant to their decision. This is also an argument in favor of assigning cases to mixtures of topics, rather than using a discrete topic model or a discrete expert coding: if the justices talk about multiple issue areas in their opinions, allowing their preferences in all those areas to predict their decisions is more reasonable than picking just one area.

There are two senses in which the estimates we derive under this approach are not unique. First, as noted previously, the LDA model combined with text is only one way to generate a matrix of weights $\lambda_{j d}$ for each vote $j$ across each dimensions $d$. Each method for defining $\lambda_{j d}$ will define a different multidimensional preference space. This is sufficient to meet the identification restrictions identified by Rivers (2003); however, it is vital that one uses information that is appropriate for defining a meaningful, multidimensional political space. This is more or less guaranteed if one uses a type of metadata that immediately provides a valid $\boldsymbol{\lambda}$ matrix. For the Supreme Court, the Spaeth issue and issue area codes provide an expert discrete issue coding, which we discuss in comparison to our estimated topics later in this paper. For legislatures, originating committee is often used as a topic coding. For textual and other sources of metadata, it is important to have a substantive justification for why the chosen metadata model provides a useful and meaningful mapping of votes onto dimensions. In our application below, we provide this justification with reference to the limitations of the Spaeth codes, by examining the details of the recovered topics, and by demonstrating that the estimates generate novel insights into preference variation on the Court.

Second, even once one has decided to fit a topic model on a particular set of texts to define the $\lambda_{j d}$, it is important to recognize that such models do not yield "definitive" topical decompositions Blei and Lafferty (2009). The idea of "topics" is useful for characterizing variation, but there are no "true topics" to discover in the data. Thus, there is no generally "correct" answer to the dimensionality issue. The performance of the models in terms of fit (as assessed by DIC) will vary 
to the extent that the topical decomposition tracks the underlying variation in the preferences of the voters. Moreover, when LDA is estimated by MCMC as in this paper, it does not generate exactly the same topics each time it is re-estimated. The appropriate way to think about this is as a descriptive model: we find $a$ set of topics that explains variation in term usage, but those topics are not fixed. For some applications, having a fixed topic coding scheme is vital, and so a supervised topic model for text should be used (Blei and McAuliffe 2007; Hopkins and King 2010). However, for exploratory analyses like the one we describe below, an unsupervised topic model works well, and does not demand any ex ante specification of political issues. Analysts must exercise substantive judgment about the political spaces they wish to use to describe preferences; they must choose whether they want to generate a space via an exploratory tool like LDA or instead use some other method that allows greater control over the recovered space.

\section{APPLICATION: THE U.S. SUPREME COURT}

The model we develop above is broadly applicable to many political institutions. The voting data modeled with the IRT model must be linked to documents which vary in term usage primarily as a function of the issues at stake in the vote. Such texts are not hard to find: legislators often have recorded debates about proposed laws, courts write opinions summarizing the issues and legal questions associated with the particular case they are deciding, and bodies like the United Nations vote on resolution and treaty texts. To illustrate the utility of our model, we employ data from the US Supreme Court. Our roll call data consist of 4321 non-unanimous Supreme Court decisions from 1949 to 2006. These include the votes of 30 justices, of whom no more than 9 were involved in any single decision. The text we associate with each decision is that of the opinions in a case. ${ }^{2}$ We employ the full text of opinions, rather than isolating specific aspects, such as the holding, because we believe the larger content of the opinion is important for establishing the mix of issues

${ }^{2}$ If one were interested in making predications about future cases, it would make sense to use legal briefs, appeals court majority opinions, or other texts that are available in advance of the case decision. 


\section{DIC for Roll Call Votes by Topic Count}

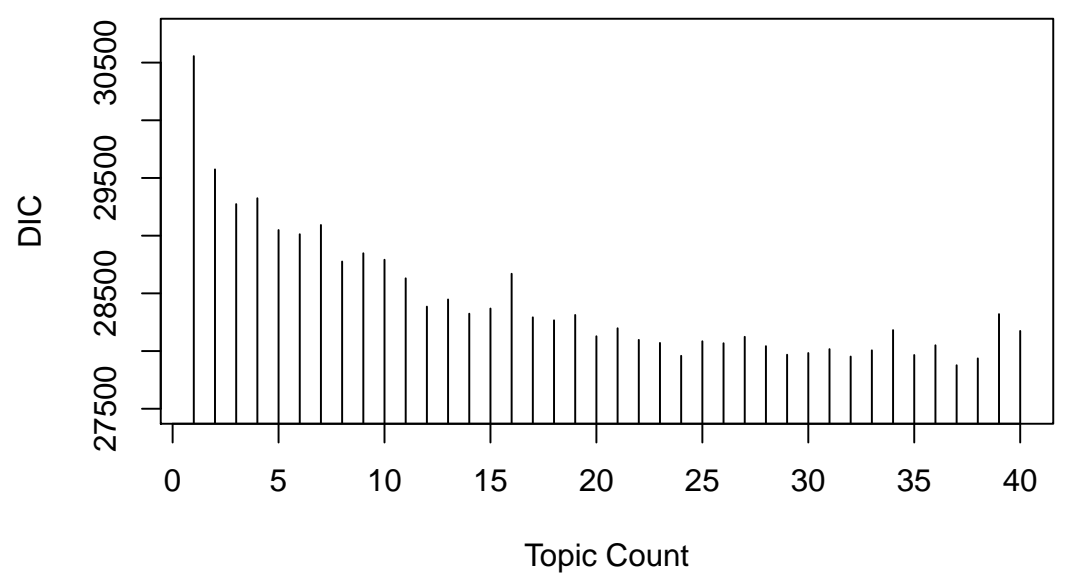

Figure 2: DIC for predicting roll call votes as a function of topic count.

considered by the Court.

In order to fit the model, the first question we must consider is the dimensionality of the model we wish to estimate: how many topics for the LDA model best fit the voting data? To roughly estimate the appropriate number of dimensions, we ran short simulations - 2000 iteration burn in; 4000 iteration sample - for a range of topic counts from 1 to 40 to find which numbers of topics lead to the best prediction of votes by the criterion of DIC as described above. Figure 2 shows the results of these simulations. We find improvement in DIC up to around 25 topics, and little improvement beyond. The predictive power of the model does not get worse either, primarily due to the cross-dimensional shrinkage of the ideal points.

There is no "correct" number of dimensions. We select 24 dimensions for further analysis because that number seems to provide a reasonable point at which further marginal decreases in the DIC are small. Just as importantly, when we look at the terms that are most characteristic of each topic, this is also around the point at which additional substantive nuance diminishes. Making this evaluation is not amenable to a statistical criterion, but we can see the principle in action by considering the topics recovered when we fit a 2D model. As Figure 2 shows, this model represents a significant improvement in fit over the one-dimensional model. The two topics recovered from 
the texts describe the two major functions of the Supreme Court: some of the terms that are most indicative of the first dimension are "act", "congress" and "federal"; while some of the terms that are most indicative of the second dimension are "trial", "jury" and "evidence". The first dimension captures constitutional review of the legislative and executive branches: acts of congress, issues of federalism, taxes, etc. The second dimension captures oversight and administration of the judiciary: criminal defendants' rights, rules of criminal and civil procedure, etc. However, as we show below when we examine the 24 dimensional fit, we can recover many more than two substantively meaningful topics, and as the DIC above indicates, this improves predictive performance. In other words, a combination of both statistical fit and substantive inspection should guide selection of dimensions.

\subsection{Estimated Topics versus Expert Coding}

Unlike most potential applications of our model, for the Supreme Court we have an existing expert coding to compare to the LDA model's assignment of texts to topics. Issue area codings are available from the Supreme Court Database (Spaeth et al. N.d.). Figure 3 is a heat map showing the distribution of Spaeth issue areas across LDA topics. We adopt the common practice of using the top three terms for each topic as a label. For example, "union", "labor", and "board" are the most distinctive terms in a topic consisting of text related to union regulation. ${ }^{3}$ While our 24 topics are necessarily distinct from the 13 issue areas, there is much in common. Relatively unpopulated Spaeth issue areas like Unions, Interstate Relations, Federal Taxation, and Miscellaneous fall heavily into a single LDA topic areas, whereas more common issue areas involve cases that mix across multiple topics.

These estimated topics turn out to be superior for predicting variation in justices' voting behavior. We compared the DIC from estimates based on a 13-dimensional LDA topic model to the DIC from estimates using the Spaeth issue area codings to define the $\lambda$ matrix, and found that the

\footnotetext{
${ }^{3}$ We do not stem the text, so some groups of terms are duplicative. With shorter texts, stemming may be necessary to get sufficient information from the texts.
} 


\section{Spaeth Issue Area by LDA Topic}

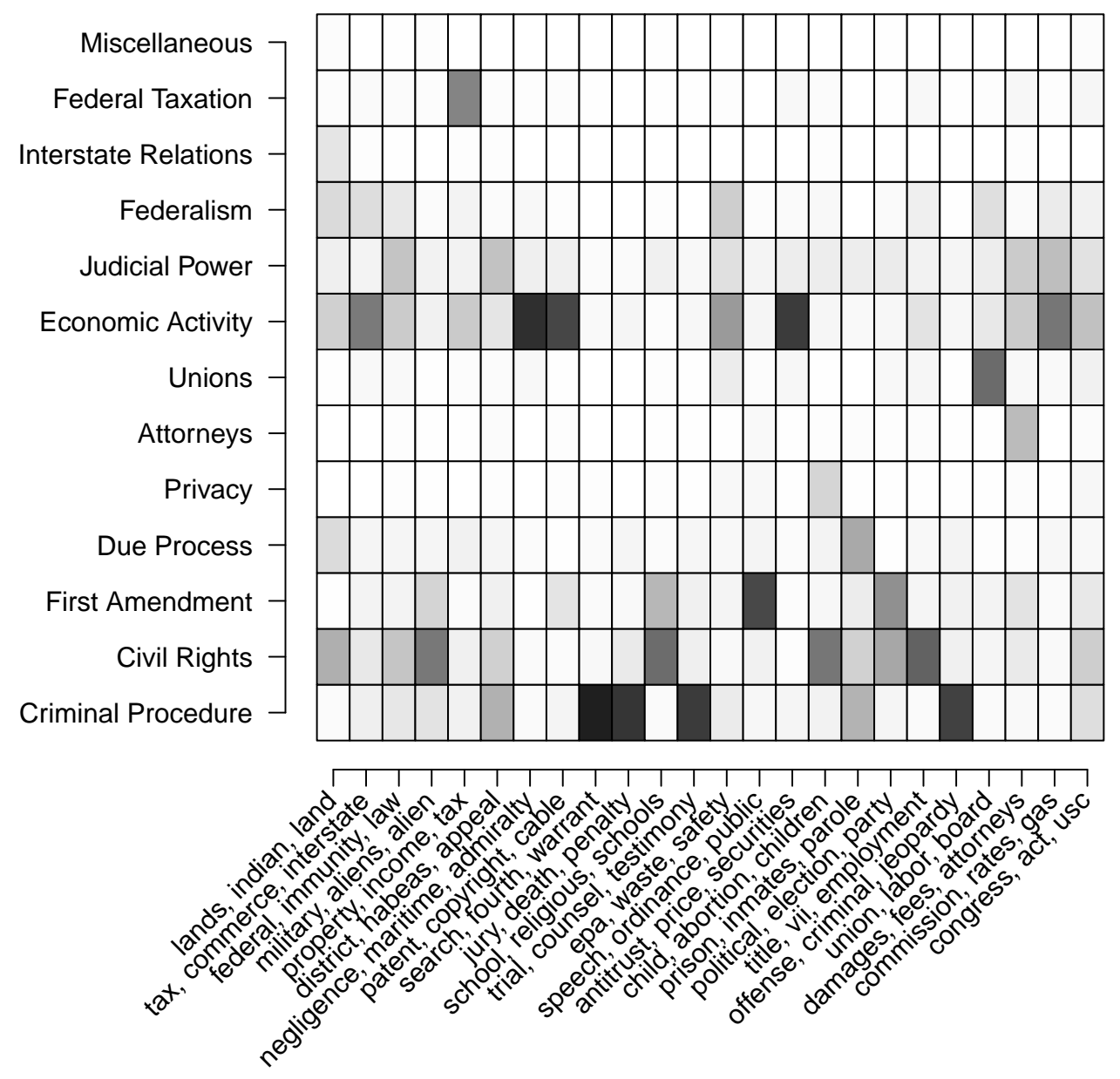

Figure 3: Spaeth issue areas versus LDA issues. Figure shows the frequency with which each Spaeth issue area is attached to each LDA topic. Darker shades correspond to more frequent appearance. 
former was lower. We then converted these 13-dimensional topic estimates from the LDA model into a discrete topic coding by assigning each case $j$ to the category $d$ which had the largest estimated $\lambda_{j d}$. Using the discretized LDA topic assignments, there was still an improvement in DIC versus the Spaeth assignments, but not as large. Thus, in a comparison of 13 dimensional models, some of the gain in prediction versus Spaeth is due to using texts rather than the Spaeth coding scheme, and some is due to allowing cases to be assigned to mixtures of topics. Further gains in prediction then arise from moving from 13 to 24 topics.

The fact that some of our gains in predictive power are due to the fact that cases can be assigned to multiple topics, with estimated weights, highlights one of the advantages of our approach versus expert coding. In matters as complex as litigation or legislation-the matters on which we often scale votes - preferences over multiple issues may influence decisions. Depending on coding rules, an expert coder might be forced to choose a single topic to assign a vote, might have the option of selecting multiple issues without specifying their relative weight, or might have the option to assign weights to topics. In the former two scenarios, we do not have the benefit of knowing how relevant different topics are; in the final scenario, the coder has a very difficult task and reliability may be low. The text-based approach avoids these pitfalls by employing a clearly-specified model of topic mixtures and relying on straightforwardly measured information: the distribution of terms in documents.

\subsection{The Supreme Court in 24 Dimensions}

Figure 4 shows the relative fraction of text in each LDA topic over time. Some topics-e.g. "negligence", "maritime", "admiralty"; and "commission", "rates", "gas" —are far more prevalent

early in the period, while others appear only after specific legislative or legal events - e.g. "title", "vii", "employment"; and "child", "abortion", "children". Consider cases dealing with the death

penalty (the topic associated with the terms "jury", "death" and "penalty"). We see a relatively low level of representation by this topic during the early period here, followed by a steady increase from about 1970 through 1990, and then a subsequent leveling off or even decrease over the next 
15 years. This pattern is consistent with qualitative studies of the death penalty, which document increased litigation during the 1970s and 1980s followed by a slight decrease during the 1990s (e.g., Walker 2009). As another example, consider the topic related to abortion cases (the topic associated with the terms "child", "abortion", and "children"). We see a spike in this topic during the 1970s, followed by a steady decrease from 1980 through 2000. This pattern comports with other studies of doctrine which show that in the wake of Roe v. Wade (1973), there was a lot of Supreme Court litigation that sought to clarify and extend the rule announced in Roe, while the Supreme Court has paid less attention to this line of doctrine since the mid-1980s (e.g., Clark and Lauderdale 2012). As a final example, consider the topic associated with the terms "district", "habeas", and "appeal". We see here a spike during the Warren Court era (1953-1968) followed by a sharp decrease during the Burger Court (1968-1986), and then a slower but steady increase during the Rehnquist Court years (1986-2005). This patterns comports with conventional understandings - namely, that the Warren Court spent a lot of time dealing with the rights of criminal defendants, that the Burger Court turned its attention away from such cases, and that the Rehnquist Court again returned to these cases (albeit from a different ideological perspective than that of the Warren Court).

Turning from the content of the Supreme Court's docket to the preference estimates, in Figure 5, we show the relative positions of the 30 justices in our data, in each issue area. Justice Douglas is not visible on the plots, as he is so far off the left edge of the scale that including him would obscure the more relevant differences between other justices. The justices are listed from top to bottom in decreasing average ideal point across all issue dimensions. The justices' rank orderings across issue dimensions are correlated, but not perfectly so. The preferences in two tax issues - "property", "income", "tax" and "tax", "commerce", "interstate" - are very weakly related to preferences in the other dimensions. We also find that the category "congress", "act", "usc", which contains generic terms related to all Court reviews of congressional statutes has an ordering that is weakly related to other issues. The more that the text of a case's opinions comes from this category, the more that text is about abstract issues related to judicial review in general, and so it is perhaps unsurprising that the typical preference ordering of the Court applies less and less in these cases. In these three areas, it is not just the case that the orderings of justices are atypical, but it is also 

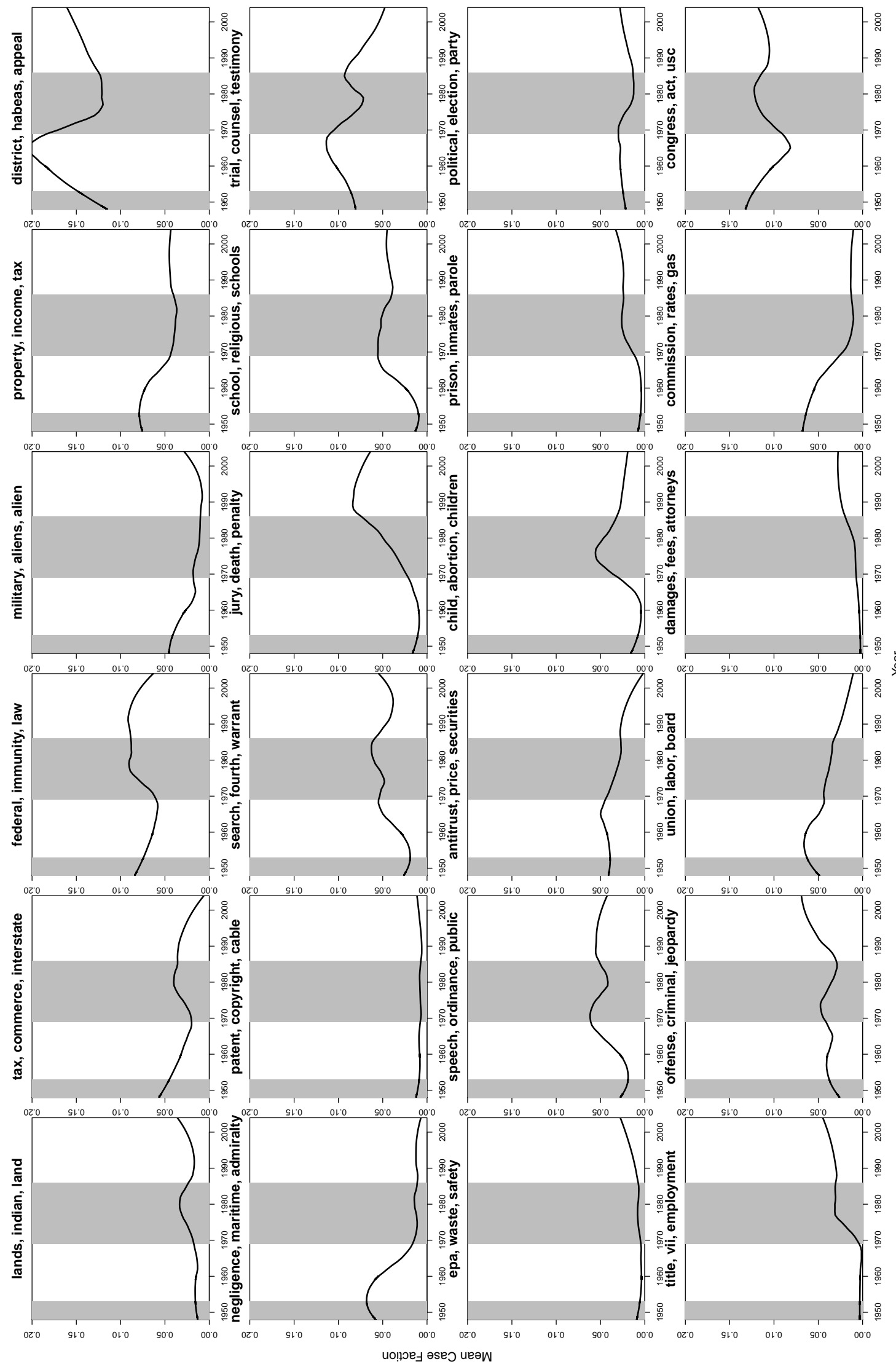

Е

:

एँ

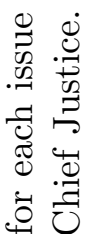

웜

范

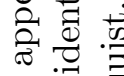

낭

응

实

过

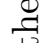

的

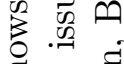

क

范茫

दै है

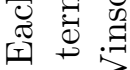

政

है

ญ.

¿

\&

敢

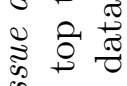

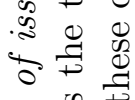

고

‥

究

全 㐘

$\ddot{\forall} \approx$

岁㟔造

总昰莺 
the case that we cannot be very confident of any ordering. There is not much difference among the justices on these issues. This result is one that is alluded to among scholars of the courts, though rarely documented (but see Martin and Quinn N.d., 4).

The model recovers a number of features that one should expect to find, providing evidence of the model's validity. For example, as noted, Justice Douglas is the left-most justice on all dimensions, while the two most conservative justices on most dimensions are Justices Thomas and Scalia (they are the top two justices depicted in each panel of Figure 5). One exception is the topic associated with the terms "property", "income", and "tax", which does not exhibit much variation in the justices' expressed preferences at all. However, the model does more than just recover well-known ideological consistencies among extremist justices; there are many examples of individual justices with peculiar views in particular issue areas. For example, it has been previously documented that Justice Black had more conservative views on issues of criminal rights than on other issues (e.g., Newman 1997; Lauderdale and Clark 2012), and this pattern is recovered here, as is apparent in the topic "search", "fourth", "warrant"; the topic "prison", "inmates", and "parole" and the topic "jury", "death", and "penalty". Taken together, the patterns depicted in Figures 3 through 5 show that our model is capturing substantively meaningful dimensions of judicial decision-making and substantively relevant variation in the justices' preferences across those dimensions. ${ }^{4}$

Figure 6 shows the location of the median for each topic, for each of the 57 years covered by our data. These issue-specific consequences of justice replacement are entirely masked by unidimensional preference estimates. For example, most models of judicial preferences suggest the Court become increasingly liberal during the Warren Court and has turned in a conservative direction since, primarily due to justice replacement. This general pattern is reflected in our estimates - the median justice moves to the left in most topics during the Warren Court. However, that overall trend has a number of interesting exceptions, which demonstrate the heterogeneity of preferences across topics. Consider the topics associated with economic issues, such as "antitrust", "price", and

\footnotetext{
${ }^{4}$ The recovered dimensions are correlated, but a secondary analysis of the dimension-specific ideal points using principle components analysis indicated that the variation across justices beyond average left-right position is not explained by one or two additional dimensions: it is issue-specific variation. We think future analyses, especially exploratory roll call analyses, may benefit from more extensive secondary analyses along these lines.
} 

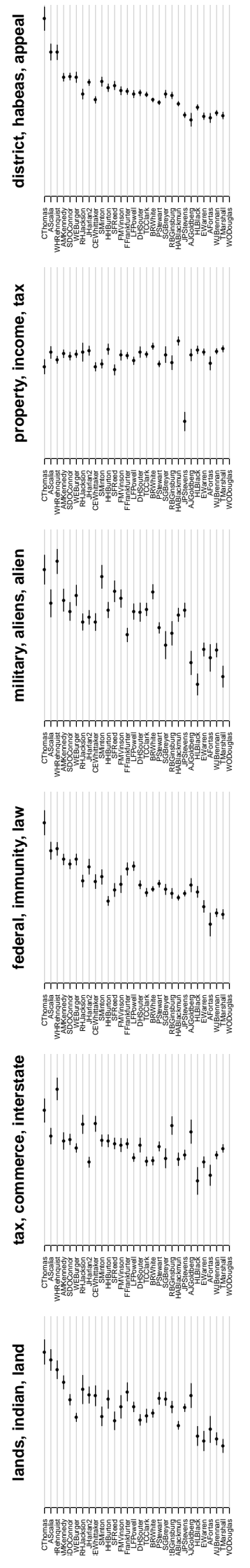
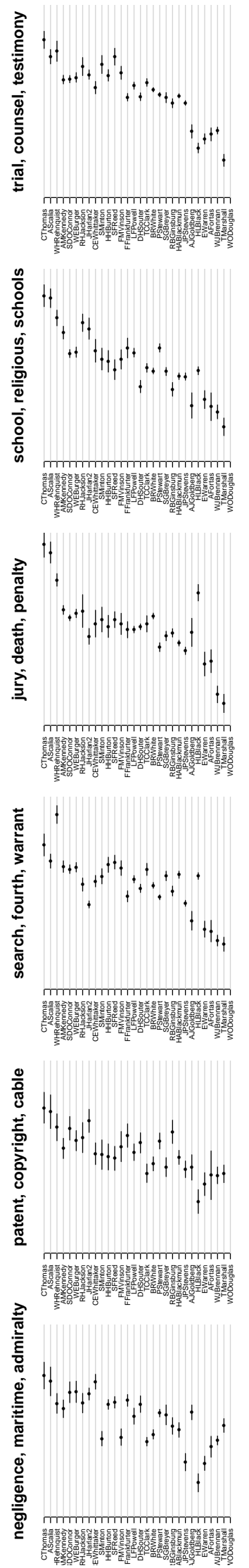
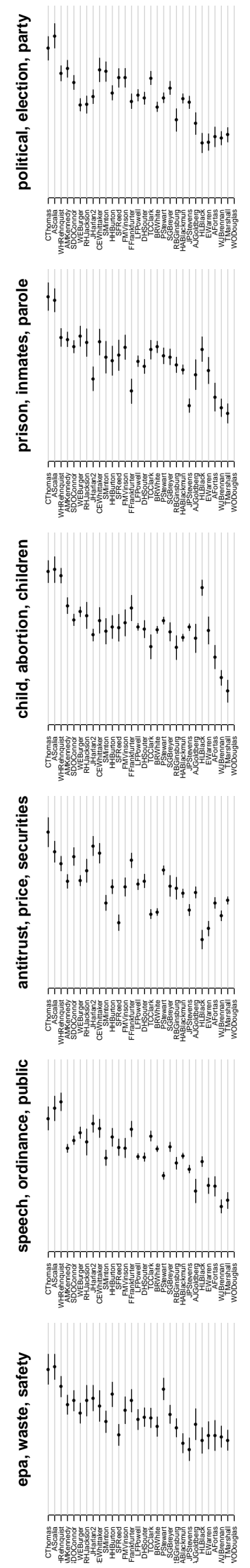
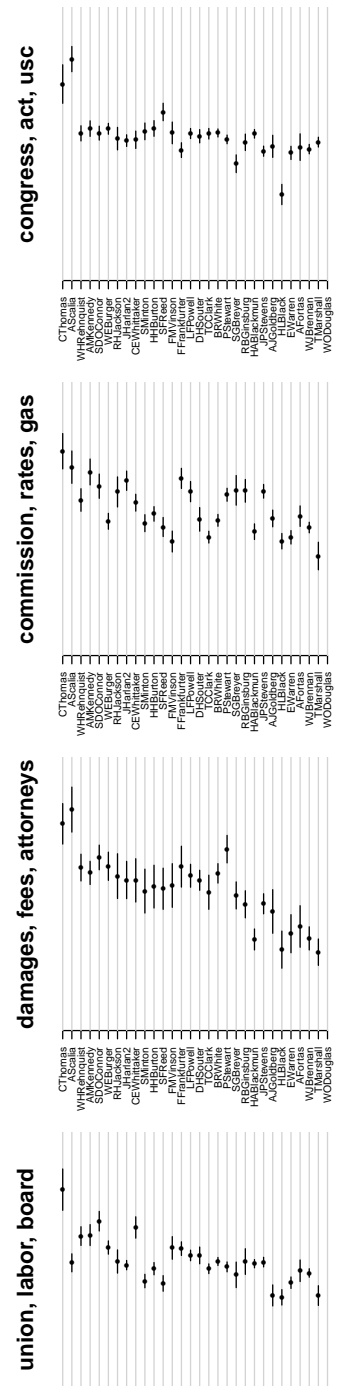

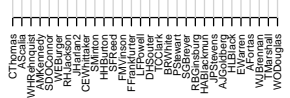
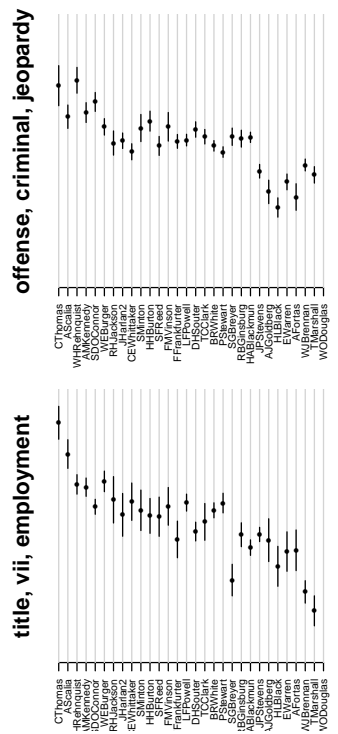

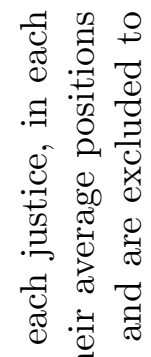

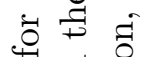

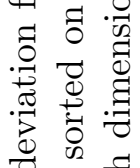

च

胥. 巳

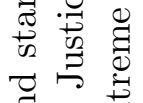

ฮี

需.

要

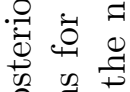

ำ

Ð્ક

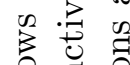

青.

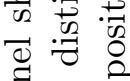

范

సี

坐

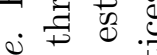

जo

के के

㐘

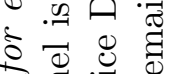

مै

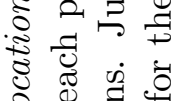

눙

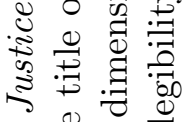

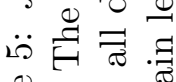

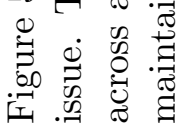


"securities"; "union", "labor", and "board"; and "commission", "rates", and "gas". These topics are associated with little change, or even conservative change, during the Warren Court. Indeed, the justices appointed by Franklin Roosevelt who served until the 1950s were particularly liberal on topics of economic regulation (they were chosen for that very reason), and as a consequence their replacements during the Warren Court actually shifted the Court to the right, rather than the left, on these topics. At the same time, we find the anticipated pattern that the Warren Court moved farthest to the left on issues relating to civil rights and civil liberties.

The location of the median justice across the various topics similarly helps identify when, and on what issues, the Court has moved in a conservative direction since the late-1960s. A conventional understanding of the Burger Court is that Nixon's attempt to move the Court to the right was a failure, though some have recently argued that this is largely because Nixon was focused on a few issues and did not really want to effect a wholesale conservative revolution on the bench (e.g. McMahon 2011). Figure 6 reveals that the Nixon appointees in fact effected a fairly dramatic conservative shift on issues of civil liberties and criminal procedure, while they brought about a much smaller shift on other issues, such as labor rights and employment discrimination, economic regulation, and religion.

This discussion of topic-by-topic preferences requires some caveats. Only a few of the cases are assigned entirely to a single topic; many cases are a mix of topics. While this motivates the structure of the model, it also raises the question of how we should interpret preferences on a single dimension. One answer is to note that the distribution of posterior assignment probabilities is highly bimodal, with posterior probabilities nearly $0 \%$ for most topics and over $90 \%$ for a single topic. Thus, many cases map mostly to a single topic. The notable exception to this pattern is the topic associated with procedural issues and statutory interpretation (congress, act, usc). Some cases are entirely about procedural issues, but among those that are not, there is often a considerable procedural question presented in a case. A second answer is that even in the absence of a case that is entirely contained within a single topic, knowing the Court's median with respect to that topic informs our understanding of how cases implicating the topic change over time. For example, at the same time as the median justice was becoming increasingly liberal on issues of free 


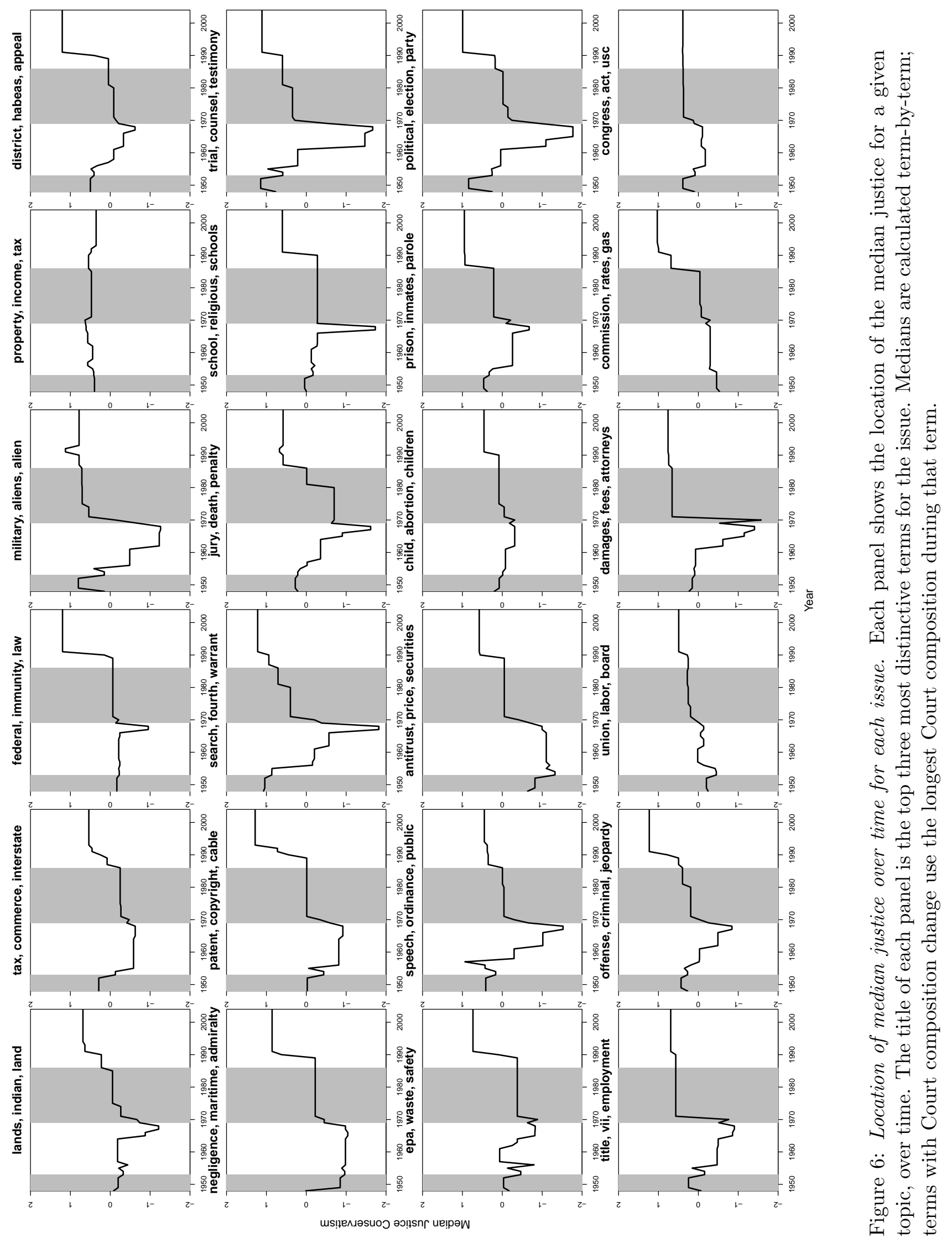


speech and criminal procedure (during the Warren Court), the median was not changing (or even becoming more conservative) on issues of religion and public schools and labor-business relations. The implication is that cases blending free speech and union issues would experience a less liberal shift than a case blending free speech and criminal procedure. The issue-specific ideal points can be thought of as indices of ideal types: measuring relative conservatism within a specific issue, recognizing that many cases will blend together multiple topics.

\section{IMPLICATIONS}

The measurement model we have proposed does more than simply introduce a substantivelygrounded multidimensional ideal point model that is portable to any number of institutional settings. It also opens the door to new theoretical questions scholars were not have previously able to study. In this section, we briefly describe three of the applications and implications of our estimates of Supreme Court ideal points: the politics of judicial nominations, the development of law, and roll-call analysis.

The politics of judicial replacement. Students of politics have spent considerable time studying the impact of executive nominations to courts, agencies and other bodies. Confirmation battles over Supreme Court nominees have become particularly contentious over the past 30 years. In this vein, the literature has increasingly focused on the extent to which any given nomination will affect the median of the Court, as that is usually seen as an important indicator of the policy consequences of a nomination (Krehbiel 2007). Our analysis demonstrates that the consequences of replacing a justice may vary across areas of the law, because the justices differ in their relative rank orderings across areas of the law Lauderdale and Clark (see also, 2012).

As an illustrative example of how an analysis of confirmation politics may play out, consider the replacement of Justice O'Connor by Justice Alito in 2005. In general, through the 1990s and early-2000s, Justices O'Connor and Kennedy were two pivotal members of the Court. With four relatively liberal justices (Stevens, Souter, Ginsburg and Breyer) and three relatively conservative justices (Rehnquist, Scalia and Thomas), how these two justices voted on any given case was often 
dispositive.

Figure 7 shows the posterior distribution of the difference between Justice Kennedy and Justice O'Connor's positions, for each of our 24 dimensions. Positive values indicate Kennedy being more conservative than O'Connor; negative values indicate Kennedy being more liberal than O'Connor. The plots reveal that we have high posterior confidence that O'Connor was to the left of Kennedy on roughly six issues, whereas Kennedy was to the left of O'Connor on roughly four issues. Importantly, this comparison helps illuminate the substantive impact of O'Connor's departure from the Court in 2005, which is widely believed to have left Kennedy as the dominant median justice on the bench (Lithwick 2006; Lane 2006). However, our estimates suggest the ideological impact of this change should depend on the subject matter.

Indeed, these expectations are borne out in the data. Table 2 compares the ideological orientation of the Court's disposition — as coded in the Supreme Court Database (Spaeth et al. N.d.) —in cases involving eight issues both before and after O'Connor's departure from the Court. In the top half of the table, we consider the cases where our preference estimates suggest her replacement by Alito should have a conservative effect-employment discrimination, abortion, the death penalty, and religious freedom. While the numbers of cases are small, we see that in each of these areas, the rate of liberal decisions has declined. In the bottom half of the table, we consider the cases where our preference estimates suggest her replacement by Alito should have little effect- securities regulation, employment arbitration, patents and copyrights, and attorneys' fees. In these four areas, we see no shift towards conservative decisions, in fact if anything there is a shift in the liberal direction since O'Connor left the Court.

In a small voting chamber like the U.S. Supreme Court, variation in preferences across issues can be highly consequential. Consider the landmark ruling in Citizens United v. FEC (2010), which held corporations may spend unlimited amounts of money on behalf of political campaigns. The ruling has had significant implications for American politics in the years since, and there is good reason to believe that the 5-4 decision would have come out the other way had Sandra Day O'Connor still been on the Court. Recent journalistic accounts note that in earlier challenges to the campaign finance restrictions, O'Connor had sided in support of the FEC, and it was only after her 


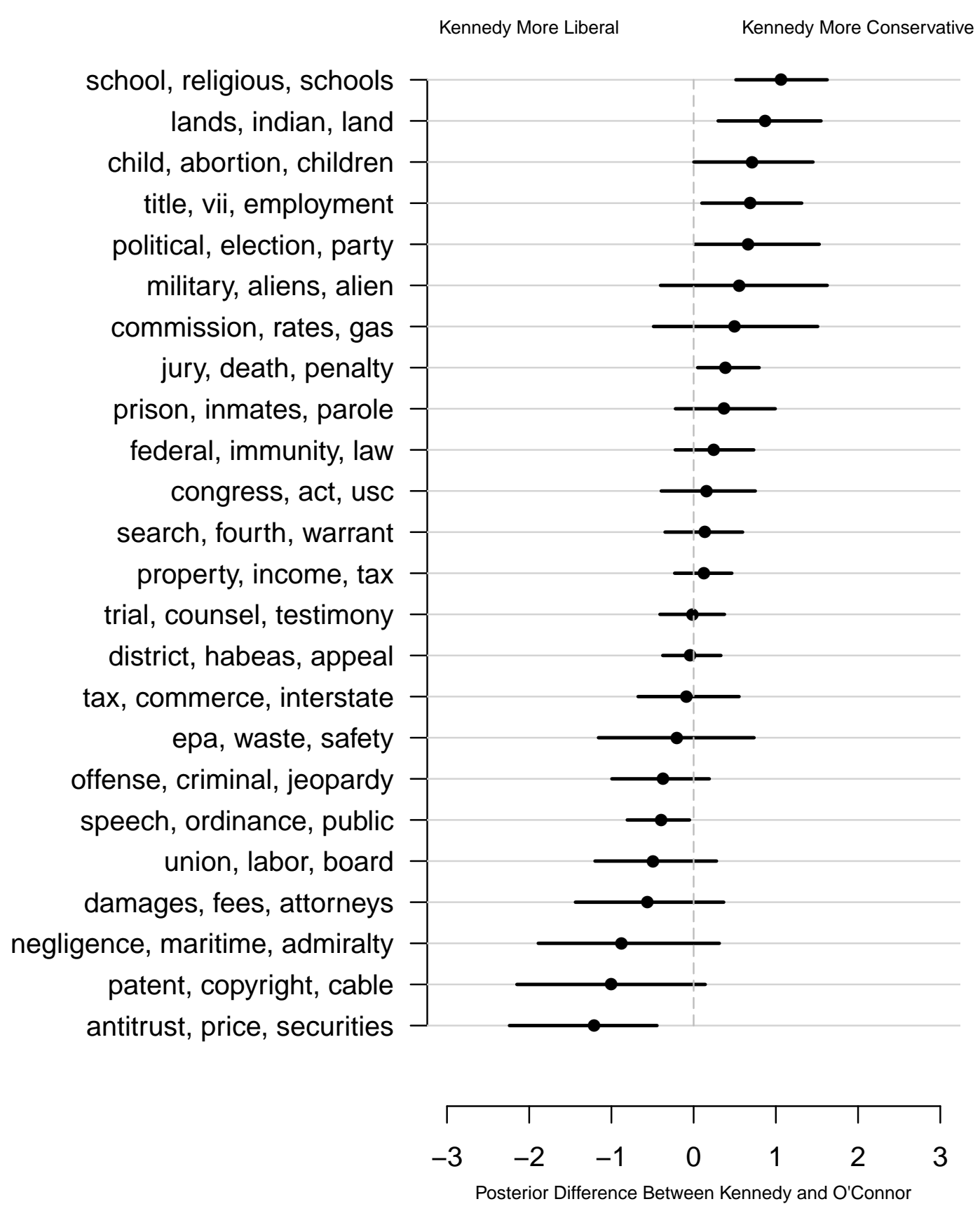

Figure 7: Comparison of Justice Kennedy's and Justice O'Connor's ideal points in each issue dimension. Each row shows the posterior distribution of the difference between Kennedy's and O'Connor's ideal points, with the median posterior and central 90\% interval depicted along the $\mathrm{x}$-axis. The label of each row is the top three most distinctive terms for the issue. 


\begin{tabular}{l|cc}
\hline & $1994-2004$ & $2005-2010$ \\
\hline \hline Kennedy More Conservative & & \\
Sex discrimination in employment & $6 / 7(86 \%)$ & $3 / 5(60 \%)$ \\
Abortion & $3 / 7(43 \%)$ & $1 / 3(33 \%)$ \\
Death penalty & $5 / 12(42 \%)$ & $3 / 12(25 \%)$ \\
Establishment of religion & $3 / 5(60 \%)$ & $0 / 1(0 \%)$ \\
& & \\
Kennedy More Liberal & $1 / 1(100 \%)$ & $5 / 5(100 \%)$ \\
Securities regulation & $2 / 5(40 \%)$ & $1 / 1(100 \%)$ \\
Employment Arbitration & $12 / 18(66 \%)$ & $8 / 10(80 \%)$ \\
Patents and copyrights & $1 / 5(20 \%)$ & $3 / 9(33 \%)$ \\
Attorneys fees & & \\
\hline
\end{tabular}

Table 2: Comparison of disposition directions in six selected issues before and after O'Connor's departure from the bench. The table compares the direction of the case disposition in six issues during the long Rehnquist Court (October Terms 1994-2005) with the Roberts Court (October Terms 2005-2010). Entries are the proportion of decisions that are coded as having liberal dispositions in the Supreme Court Database.

replacement by Justice Alito that the Court tilted in favor of corporate spending (Toobin 2012). As we see in Figure 7, Kennedy is indeed to the right of O'Connor on the "political", "election", "party" topic.

The upshot of this discussion is that we might expect different kinds of struggles to emerge during a judicial nomination, as a justice's departure may affect different issues differently. When Kennedy departs the Court, there will likely be much debate, as he is currently so pivotal on many issues. However, any given justice's departure may influence certain issues more than others; our analysis highlights the importance of considering the dimensionality of judicial voting when studying the politics of nominations and confirmations.

The development of law. A second implication and potential future application of our analysis concerns the development of law in the US Supreme Court. Scholars have long been interested in how doctrine and case-law build sequentially through a series of decisions, and much attention has been paid to the use of strategic litigation to shape development of the law. Some of that scholarship has focused on the incentives created by changing membership on the Court to being new cases. Our analysis suggests that, even given a fixed membership on the Court, a strategic litigant may be able to shape the law by framing cases in a particular way. For example, our 
analysis reveals that Justices Kennedy is relatively conservative on topics of religion and relatively liberal on topics of individual freedom.

Theoretical models of multidimensional preferences in judicial rule-making have gained more attention in recent years (Lax 2007). One of the central questions in the economic and political science analysis of legal doctrine concerns how different cases, presenting different mixes of issues, interact over time to build a body of doctrine (Kornhauser 1992; Gennaioli and Shleifer 2007). Our methodology provides an opportunity to gain empirical leverage on the theoretical tensions those models isolate. Our approach allows analysts to investigate the dimensionality of judicial voting and evaluate theoretical predictions about how different mixes of dimensions will split judges differently. This type of analysis might be particularly useful for the analysis of strategic litigation by policyminded litigants in combination with methods for scaling the content of the opinions themselves (e.g., Clark and Lauderdale 2010).

Roll-call analysis. A third implication and potential future application of our methodology extends beyond the judicial politics examples on which we have focused thus far. The method we propose for discovering and describing the dimensionality of a voting space is particularly attractive for estimating multidimensional ideal points in small chambers. However, even in the context of a large voting body, where existing methods work more reliably, our method has the advantage that the dimensions are substantively defined. The requirements for any future application are only (1) a matrix of voting data, and (2) a source of metadata that can be used to generate mixture or discrete assignments to dimensions. Here we have used the texts of judicial opinions to assign cases to a set of dimensions. Alternatively, one might use expert codings of case topics (such as the issue codes in the US Supreme Court Database, or the topic codes from the Policy Agendas Project). The critical component is that one is able to generate a matrix $\boldsymbol{\lambda}$ that defines a meaningful political space in which to map voting behavior.

The rise of widely-available metadata on political voting - such as text of debates and legislationis, we believe, a particularly promising avenue for such applications in the future. Students of supranational legislative and judicial institutions, for example, have access to increasingly extensive textual information and also are becoming increasingly interested in more nuanced descriptions 
of cleavages on the Inter-American Court of Human Rights, the European Court of Human Rights, the European Parliament, the United Nations General Assembly, and the World Trade Organization, among others. One of the most compelling applications of our method is exploratory: it can be used in conjunction with many forms of metadata to discover and summarize the nature of political cleavages in both large and small voting bodies.

\section{CONCLUSION}

The model we describe in this paper does not generate sets of ideal point estimates that we can call the ideal points of the actors. There is no true number of issues to be uncovered; the number of issues we can usefully estimate is in part a function of data density, rather than any fundamental truth about how many issues a voting body considers. Indeed, in our example, a wide range of values for the number of estimated topics all yield roughly equal values of DIC, the criterion that we use to evaluate fit. However, this limitation is fundamental to all scaling models. Ideal point estimates exist on scales that researchers create: they are useful fictions that help us describe patterns in large data sets.

Unidimensional ideal points provide especially parsimonious summaries of political conflict in legislative and judicial bodies, reducing a large matrix of voting patterns to a single measure of relative preference. But while these are useful first-order approximations to behavior, politics is not so simple as one (or even two) dimension(s). Methodological obstacles have kept scholars from getting much more from ideal point estimators than the first two dimensions. Even in two dimensions, identification and interpretation problems quickly dominate the process of analyzing roll call data: only by simultaneously examining actors with extreme positions and votes with large loadings on particular dimensions can labels be put on a standard ideal point estimates, whether those estimates come from NOMINATE, OC, or Bayesian IRT. Beyond two dimensions, these informal labeling techniques quickly become infeasible. Researchers have sought to overcome these problems by leveraging metadata to overcome identification and interpretation problems (e.g. Clinton and Meirowitz 2003; Jessee 2009; Zucco, Jr and Lauderdale 2011; Lauderdale and 
Clark 2012), though these approaches have tended to be methodologically tied to the particular institutions under study in ways that limit their general applicability.

Our approach provides better descriptions than previous ideal point estimation techniques because it addresses the reductionism problem and the labeling problem simultaneously, while also being generally applicable to the full variety of roll call data that researchers have examined. Using textual data enables more nuanced descriptions of voting behavior, with that nuance provided in terms of the actual terms that describe the issues at stake. Unsupervised text models like LDA, applied to vote-specific texts, are an excellent tool for exploratory analyses like the one we present here. Supervised text models, which impose a predefined categorization, will be useful for estimating issue preferences on particular topics of interest to researchers. More broadly, any clustering algorithm or mixture model, applied to vote-specific metadata that varies primarily by the topic of the vote, will produce a valid $\lambda$ matrix of issue weights for our modified IRT model. For example, if one had network data describing which votes were on similar issues Lauderdale and Clark (2012), one could use community detection methods Porter, Onnela and Mucha (2009) to generate a suitable discrete categorization. Given the range of metadata on votes that exists across institutions, our approach is potentially applicable to most existing roll call data sets: any voting data for which there are a set of substantively-relevant documents associated with the votes, such as recorded debates, bills, court opinions, treaties, resolutions, etc. This methodology will be especially useful for the study of small voting bodies like the Supreme Court, where estimating typical multidimensional models is difficult because there are not enough observations for each vote. Our approach will also be especially useful for highly multidimensional voting bodies like the EU Parliament Hix, Noury and Roland (2006). In a voting body like the US Congress, there is less variation beyond the first dimension to describe Poole and Rosenthal (1997), but even in Congress there are some legislators who are not fit well by a unidimensional model because their preferences vary across different issues Lauderdale (2010).

In our analysis of the US Supreme Court, we have not only documented the extent to which different subjects have dominated the Court's docket over time, but also how the justices' preferences have systematically varied across those issues. Political scientists have collected a wide range 
of roll-call data over the past two decades, and characterized one or two aggregate dimensions of conflict in many voting bodies. By leveraging metadata about votes and the increasing variety of classification techniques, we can more richly describe political cleavages.

\section{REFERENCES}

Blei, David and John D. Lafferty. 2009. Topic Models. In Text Mining: Classification, Clustering, and Applications, ed. A. Srivastava and M. Sahami. Data Mining and Knowledge Discovery Chapman \& Hall/CRC.

Blei, David M., Andrew Y. Ng and Michael I. Jordan. 2003. "Latent Dirichlet Allocation." Journal of Machine Learning Research 3:993-1022.

Blei, David M. and Jon D. McAuliffe. 2007. "Supervised Topic Models." Neural Information Processing Systems 21.

Clark, Tom S. and Benjamin Lauderdale. 2010. "Locating Supreme Court Opinions in Doctrine Space." American Journal of Political Science 54(4):871-890.

Clark, Tom S. and Benjamin Lauderdale. 2012. "The Genealogy of Law." Political Analysis 20(3):329-350.

Clinton, Joshua D. and Adam Meirowitz. 2003. "Integrating Roll Call Analysis and Voting Theory: A Framework." Political Analysis 11:381-396.

Clinton, Joshua D., Simon Jackman and Douglas Rivers. 2004. "The Statistical Analysis of Roll Call Data." American Political Science Review 98(2):355-370.

Crespin, Michael H. and David W. Rohde. 2010. "Dimensions, Issues, and Bills: Appropriations Voting on the House Floor." Journal of Politics 72(4):976-989.

Gennaioli, Nicola and Andrei Shleifer. 2007. "The Evolution of Common Law." Journal of Political Economy 115(1):43-68. 
Griffiths, Thomas L. and Mark Steyvers. 2004. "Finding Scientific Topics." Proceedings of the National Academic of Sciences 101:5228-5235.

Grofman, Bernard and Timothy J. Brazill. 2002. "Identifying the Median Justice on the Supreme Court through Multidimensional Scaling: Analysis of "Natural Courts" 1953-1991." Public Choice 112(1/2):55-79.

Heinrich, Gregor. 2009. Parameter Estimation for Text Analysis. Technical Report 2.9 Fraunhofer IGD.

Hix, Simon, Abdul Noury and Gerard Roland. 2006. "Dimensions of Politics in the European Parliament." American Journal of Political Science 50(2):494-511.

Hix, Simon and Christophe Crombez. 2005. "Extracting Ideal Point Estimates from Actors' Preferences in the EU Constitutional Negotiations." European Union Politics 6(3):353-376.

Hopkins, Daniel J. and Gary King. 2010. "A Method of Automated Nonparametric Content Analysis for Social Science." American Journal of Political Science 54(1):229-247.

Jackman, Simon. 2001. "Multidimensional Analysis of Roll Call Data via Bayesian Simulation: Identification, Estimation, Inference and Model Checking." Political Analysis 9(3):227-241.

Jeffries, Jr., John C. 1994. Justice Lewis F. Powell, Jr.: A Biography. Fordham University Press.

Jessee, Stephen. 2009. "Spatial Voting in the 2004 Presidential Election." American Political Science Review 103:59-81.

Kornhauser, Lewis. A. 1992. "Modeling Collegial Courts I: Path Dependence." International Review of Law and Economics 12:169-85.

Krehbiel, Keith. 2007. "Supreme Court Appointments as a Move-the-Median Game." American Journal of Political Science 51(2):231-240.

Lane, Charles. 2006. "Kennedy Reigns Supreme on Court." Washington Post July 2, 2006. 
Lauderdale, Benjamin E. 2010. "Unpredictable Voters in Ideal Point Estimation." Political Analysis $18(2): 151-171$.

Lauderdale, Benjamin E. and Tom S. Clark. 2012. "The Supreme Court's Many Median Justices." American Political Science Review 106(4):847-866.

Lax, Jeffrey R. 2007. "Constructing Legal Rules on Appellate Courts." American Political Science Review. 101(3):591-604.

Lithwick, Dahlia. 2006. "Swing Time.".

URL: http://www.slate.com/id/2134421/

Martin, Andrew D. and Kevin M. Quinn. N.d. "Can Ideal Point Estimates be Used as Exaplanatory Variables?" Washington University-St. Louis research note.

McMahon, Kevin J. 2011. Nixon's Court. University of Chicago Press.

Newman, Roger K. 1997. Hugo Black: A Biography. New York: Fordham University Press.

Poole, Keith T. and Howard Rosenthal. 1997. Congress: A Political-Economic History of Roll Call Voting. Oxford University Press.

Porter, Mason A., Jukka-Pekka Onnela and Peter J. Mucha. 2009. "Communities in Networks." Notices of the American Mathematical Society 56:1082-1097 \& 1164-1166.

Rivers, Douglas. 2003. "Identification of Multidimensional Spatial Voting Models." Manuscript .

Spaeth, Harold, Lee Epstein, Ted Ruger, Keith Whittington, Jeffrey Segal and Andrew D. Martin. N.d. "The Supreme Court Database.".

Spiegelhalter, D. J., N. G. Best, B. P. Carlin and A. Van der Linde. 2002. "Bayesian Measures of Model Complexity and Fit (with Discussion)." Journal of the Royal Statistical Society (Series B) 64(4):583-616.

Stern, Seth and Stephen Wermiel. 2010. Justice Brennan: Liberal Champion. Houghton Mifflin Harcourt. 
Toobin, Jeffrey. 2012. "Money Unlimited.".

Voeten, Erik. 2000. "Clashes in the Assembly." International Organization 54(2):185-215.

Walker, Thomas G. 2009. Eligible for Execution: The Story of the Daryl Atkins Case. CQ Press.

Wallach, Hanna M., David Mimno and Andrew McCallum. 2009. "Rethinking LDA: Why Priors Matter." Proceedings of the 23rd Annual Conference on Neural Information Processing Systems

Zucco, Jr, Cesar and Benjamin E. Lauderdale. 2011. "Distinguishing Between Influences on Brazilian Legislative Behavior." Legislative Studies Quarterly . 